\title{
Comprehensive population-based determination of pediatric multiple sclerosis health care costs
}

\section{OPEN}

Melissa A. Wright, BS

E. Kent Korgenski, MS

Tyler Bardsley, MS

Joshua L. Bonkowsky,

$\mathrm{MD}, \mathrm{PhD*}$

Meghan S. Candee, MD, MS*

Correspondence to

Dr. Candee:

meghan.candee@hsc.utah.edu

\section{ABSTRACT}

Objective: To determine the health care costs associated with pediatric multiple sclerosis (MS).

Methods: We performed a retrospective analysis of all patients with MS 18 years of age or younger who were diagnosed or treated between 2002 and 2012 in a population-based cohort. Demographics and health care costs were extracted from the Intermountain Healthcare Enterprise Data Warehouse. Patients were divided into high-cost (>84th percentile) and low-cost groups and differences in health care utilization between the groups were analyzed.

Results: Fifty-seven pediatric patients with MS were identified. Health care costs for the cohort totaled more than $\$ 1.5$ million over the 10 -year period, with the top 16th percentile of patients contributing nearly two-thirds. Outpatient visits represented the majority of health care encounters and expenditures, accounting for $83.1 \%$ of total costs. Costs per encounter were highest for inpatient stays, averaging $\$ 2,924$ per stay.

Conclusions: The burden of health care expenses for pediatric patients with MS is significant. Expenditures related to outpatient visits were the largest contributor to costs, but inpatient stays were the most costly per encounter. A small proportion of patients incurred the bulk of costs and spent significantly more time receiving care compared to the majority of patients. Avoidance of inpatient treatment and efficient outpatient management are potential areas for health care cost reduction and improvement in care. Neurol Neuroimmunol Neuroinflamm 2017;4:e314; doi: $10.1212 / \mathrm{NXI} .0000000000000314$

\section{GLOSSARY}

EDW = Enterprise Data Warehouse; ICD-9 = International Classification of Diseases-9; IH = Intermountain Healthcare; MS $=$ multiple sclerosis

Pediatric multiple sclerosis (MS) with onset before age 18 years represents up to $10 \%$ of patients with MS. ${ }^{1}$ Overall progression of disease, which often has a relapsing-remitting course in children, is slow compared with adults. ${ }^{2}$ However, irreversible disability is reached 10 years sooner. ${ }^{3}$ By age 35 years, half of pediatric patients with MS have had secondary progression of disease. $^{1}$

Chronic, disabling neurologic diseases carry a high burden of health care costs and resource utilization. Pediatric patients with neurologic impairments account for $29 \%$ of charges at children's hospitals. ${ }^{4}$ Per-patient health care costs in adult-onset MS are estimated at $\$ 34,000$ annually and $\$ 2.2$ million over a lifetime. ${ }^{5}$ We established a population-based cohort of pediatric MS patients in order to determine the burden of health care costs for patients and families.

METHODS Standard protocol approvals, registrations, and patient consents. The University of Utah's and Intermountain Healthcare (IH)'s Institutional Review Boards approved this retrospective database and chart review study; informed consent was waived.

*These authors contributed equally to this work.

From the School of Medicine (M.A.W.), Study Design and Biostatistics Center (T.B.), Department of Biostatistics (T.B.), and Department of Pediatrics, Division of Pediatric Neurology (J.L.B., M.S.C.), University of Utah; and Intermountain Healthcare (E.K.K.), Salt Lake City.

Funding information and disclosures are provided at the end of the article. Go to Neurology.org/nn for full disclosure forms. The Article Processing Charge was paid by Alicia Hughes (on behalf of Division of Pediatric Neurology at University of Utah).

This is an open access article distributed under the terms of the Creative Commons Attribution-NonCommercial-NoDerivatives License 4.0 (CC BY-NC-ND), which permits downloading and sharing the work provided it is properly cited. The work cannot be changed in any way or used commercially without permission from the journal. 
Cohort identification. IH is a large, not-for-profit health care system in the Intermountain West containing over 185 clinics and 22 hospitals, including the only children's hospital in Utah. IH maintains records of hospital, emergency department, clinic, laboratory, pharmacy, and home health visits in an electronic record format. A cohort of all patients with pediatric MS presenting between 2002 and 2012 was compiled; follow-up and inclusion of cost data were through December 31, 2013. Cases were identified through a computerized search of diagnosis codes related to demyelinating diseases (ICD-9 323.82, 340.x, 341.x, 377.3, 323.x). Patients who met McDonald diagnostic criteria for diagnosing pediatric MS were included and verified by manual chart review. ${ }^{6}$ Chart review was conducted by one researcher (M.A.W.) and confirmed by a reviewer (M.S.C.) with a second reviewer (J.L.B.) available to address discrepancies when needed.

Incidence. The cohort included all infants born in Utah between 1985 and 2012. Annual birth rates were utilized to estimate the total population count. Life table method analysis was used to calculate the hazard rate of MS by each year of age as well as the overall incidence. Left truncation was used to ensure accurate risk sets at each year.

Cost and encounter data. IH maintains an Enterprise Data Warehouse (EDW), which contains financial data for patient encounters. The EDW was queried using unique identifiers for each patient to obtain comprehensive cost information pertaining to imaging, laboratory, pharmacy, clinic visits, hospital stays, and amount of time spent receiving care. Costs were categorized by type (diagnostics, therapeutics, room overhead) as well as by setting (outpatient, inpatient, emergency department), and were adjusted to 2014 US dollars (see Nelson et al. ${ }^{7}$ for detailed definitions of cost groups). The EDW does not maintain data for professional practitioner fees, which were therefore not included in total costs. Lost days were defined by total number of days spent receiving care during the 10 -year period.

Cost groups. The cohort was ordered by total cost per patient, with the top 16th percentile of patients identified as the highcost group and the bottom 84th percentile representing the low-cost group. Differences in demographics and health care burden data between the cost groups were compared. Twotailed $p$ values were calculated using unpaired $t$ test or Fisher exact test.
RESULTS Incidence and demographics. We identified 57 pediatric patients with MS treated at an IH facility between 2002 and 2012. The annual mean incidence of pediatric MS in Utah was 0.57 cases per 100,000 pediatric population, with a prevalence of 4.65 per 100,000. Demographic information is summarized in table 1.

Health care burden. Total costs for the cohort over the 10 -year period amounted to greater than $\$ 1.5$ million. The majority of costs came from outpatient care, accounting for $\$ 1,256,969$, or $83.1 \%$ of total costs. Inpatient expenses represented $13.6 \%$, with emergency department visits adding only $3.3 \%$. Inpatient visits were more costly at $\$ 2,924$ per encounter. When cost was divided by type, room overhead charges were the largest source, totaling $\$ 701,642$ or $46.4 \%$. Therapy and diagnostic expenditures accounted for $27.9 \%$ and $25.7 \%$, respectively (table 2).

A high-cost group, consisting of the 9 patients whose costs made up the top $16 \%$ of the cohort, incurred $63 \%$ of total costs. The mean cost of medical care per patient in this group was $\$ 105,166$, compared to $\$ 11,778$ in the low-cost group. Across all settings, mean costs per encounter were higher for the high-cost group ( $\$ 1,255$ vs $\$ 772$ ). Over the study period, the entire cohort lost 6,092 total days of work/school/potential productivity. High-cost patients averaged 107 lost days, with low-cost patients averaging half that amount. The number of encounters totaled 1,486 , with a mean of 84 encounters per high-cost patient and 15 per low-cost patient. The high-cost group averaged 12 MRIs per patient compared to 5 in the low-cost group (table 3).

DISCUSSION This study evaluates the burden and cost of health care for pediatric patients with MS.

Table 1 Demographic and clinical characteristics of the pediatric multiple sclerosis cohort

\begin{tabular}{|c|c|c|c|c|}
\hline Demographics & All patients & High-cost patients & Low-cost patients & p Value \\
\hline Sample size, $n$ & 57 & 9 & 48 & - \\
\hline Female, n (\%) & 32 (56.0) & $3(33.3)$ & $29(60.4)$ & 0.16 \\
\hline \multicolumn{5}{|l|}{ Race/ethnicity, n (\%) } \\
\hline White (including Hispanic) & $47(82.5)$ & $7(77.8)$ & 40 (83.3) & 0.65 \\
\hline Asian & $2(3.5)$ & $0(0)$ & $2(4.2)$ & 1 \\
\hline African American & $1(1.7)$ & $1(11.1)$ & $0(0.0)$ & 0.16 \\
\hline Not reported & 7 (12.3) & $1(11.1)$ & 6 (12.5) & 1 \\
\hline Age at diagnosis, y, mean (range) & $15.4(6-18)$ & $14.6(9-18)$ & $15.4(6-18)$ & 0.47 \\
\hline $\begin{array}{l}\text { Length of time from symptom onset } \\
\text { to diagnosis, y, mean (range) }\end{array}$ & $0.57(0-4.6)$ & $0.72(0-3.6)$ & $0.54(0-4.6)$ & 0.66 \\
\hline Length of time in study, y, mean (range) & $4.49(0-11)$ & $6.56(3-10)$ & $4.10(0-11)$ & 0.04 \\
\hline
\end{tabular}

Unpaired $t$ test (age, length of time to diagnosis) or Fisher exact test (all others) were used to calculate 2-tailed $p$ values. 


\begin{tabular}{|c|c|c|c|c|}
\hline \multirow{2}{*}{$\begin{array}{l}\text { Table } 2 \\
\text { Setting }\end{array}$} & \multicolumn{4}{|c|}{ Health care costs by setting and type } \\
\hline & Total costs, USD & Percent of total & Mean per-patient cost, USD & Mean per-encounter, USD \\
\hline \multicolumn{5}{|l|}{ All patients } \\
\hline All settings & $1,511,828$ & 100 & 26,523 & 1,017 \\
\hline Outpatient & $1,256,969$ & 83.1 & 22,052 & 970 \\
\hline Inpatient & 204,708 & 13.6 & 3,591 & 2,924 \\
\hline Emergency & 50,151 & 3.3 & 880 & 418 \\
\hline \multicolumn{5}{|l|}{ High-cost group } \\
\hline All settings & 946,470 & 100 & 105,166 & 1,255 \\
\hline Outpatient & 871,295 & 92.1 & 96,810 & 1,232 \\
\hline Inpatient & 61,977 & 6.55 & 6,886 & 2,817 \\
\hline Emergency & 13,224 & 1.4 & 1,469 & 528.96 \\
\hline \multicolumn{5}{|l|}{ Low-cost group } \\
\hline All settings & 565,330 & 100 & 11,778 & 772 \\
\hline Outpatient & 385,674 & 68.2 & 8,035 & 654 \\
\hline Inpatient & 142,731 & 25.3 & 2,974 & 2,973 \\
\hline Emergency & 36,927 & 6.5 & 769 & 388 \\
\hline \multicolumn{5}{|l|}{ All patients } \\
\hline Room overhead & 701,842 & 46.4 & 12,310 & - \\
\hline Diagnostics & 387,754 & 25.7 & 6,802 & - \\
\hline Therapy & 422,232 & 27.9 & 7,411 & - \\
\hline \multicolumn{5}{|l|}{ High-cost group } \\
\hline Room overhead & 540,965 & 53.6 & 60,107 & - \\
\hline Diagnostics & 124,095 & 12.3 & 13,788 & - \\
\hline Therapy & 344,696 & 34.1 & 38,300 & - \\
\hline \multicolumn{5}{|l|}{ Low-cost group } \\
\hline Room overhead & 160,677 & 32 & 3,347 & - \\
\hline Diagnostics & 263,659 & 52.5 & 5,493 & - \\
\hline Therapy & 77,736 & 15.5 & 1,620 & - \\
\hline
\end{tabular}

Cost groups evaluated by setting (as defined by outpatient, inpatient, or emergency department encounters) and by type (costs associated with room overhead, diagnostics, or therapy). Costs are shown for all patients, high-cost patients (top 16th percentile, $n=9$ patients), and low-cost patients (bottom 84th percentile, $n=48$ ).

Outpatient services were the primary contributor to costs. Inpatient stays, although a smaller proportion of total costs, were 3 times as expensive in their average cost per encounter. The indirect burden of health care for families was apparent, with patients spending an average of 10 days per year receiving medical care.

Table 3 Burden of health care for pediatric patients with multiple sclerosis and their families

$\begin{array}{lllll}\text { Category } & \text { Mean, total (range) } & \text { High-cost mean, total (range) } & \text { Low-cost mean, total (range) } & \mathbf{p} \text { Value } \\ \text { Total encounters } & 26.1(1,486,1-308) & 83.8(754,31-308) & 15.3(732,1-54) \\ \text { Outpatient visits } & 22.7(1,296,0-294) & 78.6(707,26-294) & 12.3(589,0-43) \\ \text { Inpatient stays } & 1.2(70,0-6) & 2.4(22,1-6) & 1.0(48,0-4) & 0.05 \\ \text { Emergency room visits } & 2.1(120,0-40) & 2.8(25,0-10) & 2.0(95,0-40) \\ \text { MRIs } & 5.6(318,1-32) & 11.6(104,3-32) & 4.5(214,1-13) & 0.13 \\ \text { Lost days } & 107(6,092,1-1,450) & 379(3,415,64-1,450) & 55.8(2,677,1-394)\end{array}$

Number of encounters at Intermountain Health care facilities, categorized by outpatient, inpatient, or emergency visits. Number of MRIs is also shown. Lost days calculated by totaling the length of stay for encounters. $p$ Values between the 2 cost groups were calculated using unpaired $t$ tests. 
Our population-based cohort's incidence of pediatric MS was similar to previous reports. ${ }^{8}$

A minority of the patient cohort accounted for the majority of cost. The high-cost group had statistically more encounters per patient, and, in particular, more outpatient visits. The definition of a high-cost group is based on prior cost studies with skewed (non-normal) distributions. ${ }^{7,9}$ High-cost patients averaged higher costs per encounter, more MRIs, a greater number of days spent receiving care, and had a longer average length of time in the study. It is unclear whether extending the study period would result in the same disparities.

Sex, race, age at onset, and length of time to diagnosis were not predictive of cost group. Clinical characteristics of patients were analyzed, but underpowered to reveal significant differences between groups. It is not clear whether greater health care costs for the high-cost cohort relate to disease severity and a need for closer management or to overutilization of resources. Future studies can address whether the high-cost group represented a distinct pediatric MS disease subtype or had other features accounting for the more severe course.

A limitation of this study is that the cost totals do not include costs for physician services. Costs described are those applied to patients by the health care system, and do not account for insurance coverage. They also do not include indirect and out-ofpocket costs, such as those associated with travel to appointments or lost wages, which families of pediatric patients with MS are likely to incur. Our study represents a single health care system (IH) over a 10 -year period. While a significant majority of specialty pediatric health care in Utah $(>90 \%)$ is provided through $\mathrm{IH}$, we cannot comment on the potential costs of health care services obtained outside of IH. While Utah's outmigration rate is among the lowest in the United States, ${ }^{10}$ patients may have moved out of the state and been lost to follow-up. The data are affected by the varying duration of time each patient spent in the study. Our analysis did not use any imputed data or last results carried forward approach. Thus, while it could not model a complete longitudinal history of pediatric MS costs, it provides specific concrete values. We included cost data from patients who were pediatric (age $<19)$ at presentation but who, during the course of data collection (20022013), may have aged out. As such, our reported costs likely underestimate the actual health care burden.

Although costs for pediatric patients with MS are less than those found in similar studies of adults, ${ }^{5}$ the costs represent only the earliest stages of a chronic, progressive disease. While pediatric MS is associated with slower progression, it has earlier onset of disability. These data represent only a small proportion of the costs that the cohort will incur over a lifetime. Given the high cost of inpatient encounters, efforts to maintain efficient, high-quality outpatient management and avoid hospital stays may be a means of effective cost control and improved patient care.

\section{AUTHOR CONTRIBUTIONS}

M.A. Wright contributed to study design/conceptualization, data interpretation, and manuscript drafting/revision. E.K. Korgenski performed data analysis. T. Bardsley contributed to data interpretation and manuscript drafting/revision. J.L. Bonkowsky contributed to study design/ conceptualization, data interpretation, and manuscript drafting/revision. M.S. Candee contributed to study design/conceptualization, data interpretation, and manuscript drafting/revision.

\section{STUDY FUNDING}

No targeted funding.

\section{DISCLOSURE}

M. Wright, K. Korgenski, and T. Bardsley report no disclosures. J. Bonkowski receives publishing royalties from CRC Press and research support from NIH, European Leukodystrophy Association, and March of Dimes Foundation. M. Candee reports no disclosures. Go to Neurology.org/nn for full disclosure forms.

Received March 10, 2016. Accepted in final form November 1, 2016.

\section{REFERENCES}

1. Thomas T, Banwell B. Multiple sclerosis in children. Semin Neurol 2008;28:069-083.

2. Ghezzi A. Therapeutic strategies in childhood multiple sclerosis. Ther Adv Neurol Disord 2010;3:217-228.

3. Renoux C, Vukusic S, Mikaeloff Y, et al. Natural history of multiple sclerosis with childhood onset. N Engl J Med 2007;356:2603-2613.

4. Berry J, Poduri A, Bonkowsky JL, et al. Trends in resource utilization by children with neurological impairment in the United States inpatient health care system: a repeat crosssectional study. PLoS Med 2012;9:e1001158.

5. Whetten-Goldstein K, Sloan FA, Goldstein LB, Kulas ED. A comprehensive assessment of the cost of multiple sclerosis in the United States. Mult Scler 1998;4:419-425.

6. Sadaka Y, Verhey LH, Shroff MM, et al. 2010 McDonald criteria for diagnosing pediatric multiple sclerosis. Ann Neurol 2012;72:211-223.

7. Nelson C, Mundorff MB, Korgenski KE, Brimley CJ, Srivastava R, Bonkowsky JL. Determinants of health care utilization in a population-based leukodystrophy cohort. J Pediatr 2013;162:624-628.

8. Langer-Gould A, Zhang JL, Chung J, Yeung Y, Waubant E, Yao J. Incidence of acquired CNS demyelinating syndromes in a multiethnic cohort of children. Neurology 2011;77:1143-1148.

9. Keren A, Zaoutis TE, Saddlemire S, Luan XQ, Coffin SE. Direct medical cost of influenza-related hospitalizations in children. Pediatrics 2006;118:e1321-e1327.

10. Utah Governor's Office. Available at: business.utah.gov/ publications/population-3/. Accessed August 5, 2016. 


\section{Neurology \\ Neuroimmunology \& Neuroinflammation}

\section{Comprehensive population-based determination of pediatric multiple sclerosis health care costs}

Melissa A. Wright, E. Kent Korgenski, Tyler Bardsley, et al.

Neurol Neuroimmunol Neuroinflamm 2017;4;

DOI 10.1212/NXI.0000000000000314

This information is current as of December 19, 2016

\section{Updated Information \& \\ Services}

References

Subspecialty Collections

Permissions \& Licensing

Reprints including high resolution figures, can be found at:

http://nn.neurology.org/content/4/1/e314.full.html

This article cites 9 articles, 0 of which you can access for free at: http://nn.neurology.org/content/4/1/e314.full.html\#\#ref-list-1

This article, along with others on similar topics, appears in the following collection(s):

Adolescence

http://nn.neurology.org//cgi/collection/adolescence

All Pediatric

http://nn.neurology.org//cgi/collection/all_pediatric

Cost effectiveness/economic

http://nn.neurology.org//cgi/collection/cost_effectiveness_economic_

Multiple sclerosis

http://nn.neurology.org//cgi/collection/multiple_sclerosis

Quality of life

http://nn.neurology.org//cgi/collection/quality_of_life

Information about reproducing this article in parts (figures,tables) or in its entirety can be found online at:

http://nn.neurology.org/misc/about.xhtml\#permissions

Information about ordering reprints can be found online:

http://nn.neurology.org/misc/addir.xhtml\#reprintsus

Neurol Neuroimmunol Neuroinflamm is an official journal of the American Academy of Neurology.

Published since April 2014, it is an open-access, online-only, continuous publication journal. Copyright $\odot$ 2016 American Academy of Neurology. All rights reserved. Online ISSN: 2332-7812.

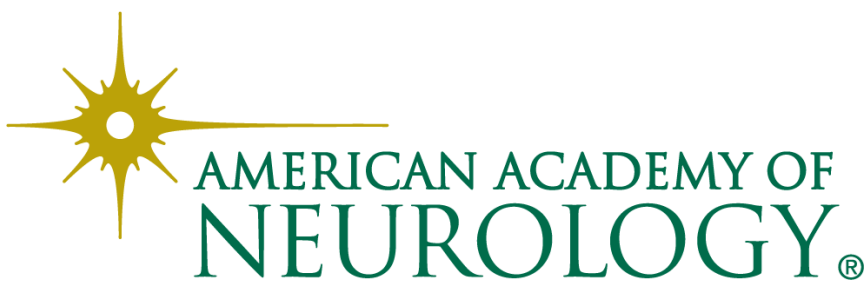

